\title{
Modification of industrial divinyl rubber by oxidative chlorophosphorylation and assess-ment of metal ion removal efficiency of obtained polymer sorbent
}

\author{
Vagif M. Akhmedov 1,3,*, Sulaiman Alfadul', Abel M. Maharramov', Abdulsaid A. Azizov' ${ }^{1}$, \\ Rasim M. Alosmanov' ${ }^{1}$, Irada A. Buniyad-Zadeh ${ }^{1}$
}

${ }^{1}$ Baku State University, Chemistry Department, Z.Khalilov str., 23, Baku, AZ1148 Azerbaijan

${ }^{2}$ King Abdulaziz City for Science \&Technology, Riyadh, Saudi Arabia

${ }^{3}$ Institute of Chemical Problems, H.Javid ave., 29, Baku, AZ1143, Azerbaijan

"Corresponding author: e-mail: advesv@gmai.com

\begin{abstract}
The main goal of this study was the preparation of materials containing phosphoric func-tionalities on the base of industrial polymer - divinyl rubber and the assessment of their removal efficiency of heavy metals from aqueous solutions. The new method concerns the oxidative chlo-rophosphorylation of divinyl rubber by $\mathrm{PCl}_{3}$ with the following modification of obtained inter-mediates to create $-\mathrm{PO}(\mathrm{OH})_{2},-\mathrm{OPO}(\mathrm{OH})_{2}$ groups in the polymer chain. The obtained modified polymers get some new properties such as complex formation and capability for ion exchange. The nature and distribution of phosphoric functionalities in the polymer were studied by the methods of NMRand FTIR- spectroscopy, thermal analysis and scanning electron microscopy. The sorption properties of synthesized polymers towards some cations $\left(\mathrm{Cu}^{+2}, \mathrm{Ni}^{+2}, \mathrm{Co}^{+2}\right.$ and $\left.\mathrm{Zn}^{+2}\right)$ from water solutions have been tested. It has been shown that the metal removal efficiency of prepared material depends on $\mathrm{pH}$ of medium, initial concentration and type of metal ions.
\end{abstract}

Keywords: Divinyl rubber, modification by chlorophosphorylation, nature and distribution of phosphoric functionalities in the polymer matrix, heavy metal ions, sorption.

\section{INTRODUCTION}

Heavy metal pollutions are one of the main problems of the ecosystem. Heavy metals are commonly found in large quantities in industrial wastewaters. Most of them are toxic and detrimental to people, animals and plants, and even in small amounts they can cause severe health problems ${ }^{1,2}$. Therefore, in order to combat the problem of water contamination, studies on the removal of heavy metals from various waters are making steady headway.

The traditional approaches for removing metal ions from aqueous solutions include reagent treatment, ion exchange and membrane technology $y^{3-6}$. The sorption methods are the most useful, readily available, and simple for purification ${ }^{7-9}$. Sorption processes with application of organic and inorganic sorbents are most commonly used for water purification. The main problem concerns the selection of low cost sorbents with high sorption capacity, which could provide effective purification.

Some synthetic polymers, copolymers and their derivatives were widely investigated as adsorbents ${ }^{10-16}$. The strongly acidic resins are the most employed ion exchangers in operations for cation separations from industrial wastewaters ${ }^{17,18}$. Among them the sulphonic acid cation exchangers are very common. They are usually based on styrene-divinylbenzene matrixes and cross-linked polymers of acrylic and methacrylic acids ${ }^{\mathbf{1 9 - 2 1}}$. The former being strongly acidic performs very well in wide range of $\mathrm{pH}$, but lacks selectivity, the latter being weakly acidic, displays enhance selectivity towards divalent metal cations.

In recent years, selective metal ion removal with phosphorus-containing polymeric sorbents has been studied by several investigators ${ }^{22-24}$. Synthesis of polymers with various types of phosphoric functionalities was reported and their complexing properties with metals were studied. It was found that in vinylbenzyl chloride-styrene- -divinylbenzene copolymer based sorbent with two types of functionalities, sulphonic groups contributed only to hydrophilicity of the resin, thus increasing transport of ions, whereas phosphonic groups were responsible for observed selectivity of the resin ${ }^{25}$.

However, almost all above prepared sorbents have been obtained by multi-steps synthesis. The first time, we worked out synthesis of ion exchangers with phosphoric functionalities in soft conditions by oxidative chlorophosphorylaton of polymers containing double bonds in chain $^{26}$. The scope of the present study was to obtain new low cost phosphorus-containing ion exchangers based on industrial polymer-divinyl rubber and evaluate their sorption ability with respect to cations of heavy metals.

\section{MATERIAL AND METHODS}

\section{Reagents}

Synthetic divinyl rubber (SDR), a product of butadiene polymerization, containing approximately $90 \%$ 1.4 cis-units was obtained from Voronezh Synthetic Rubber Manufactory, Russia. The polymer sample (Molecule weight - 120.000) was dissolved in benzene, then precipitated with methanol and dried at $323 \mathrm{~K}$ under vacuum prior to use. The following analytical reagent-grade chemicals were obtained from commercial sources and were used as received without further purification: $\mathrm{PC}_{3}, \mathrm{CC1}_{4}, \mathrm{HC1}, \mathrm{NH}_{4} \mathrm{OH}, \mathrm{CH}_{3} \mathrm{COOH}$, $\mathrm{Co}\left(\mathrm{NO}_{3}\right)_{2} \cdot 6 \mathrm{H}_{2} \mathrm{O}, \mathrm{Ni}\left(\mathrm{NO}_{3}\right)_{2} \times 6 \mathrm{H}_{2} \mathrm{O}, \mathrm{Cu}\left(\mathrm{SO}_{4}\right)_{2} \times 5 \mathrm{H}_{2} \mathrm{O}$ and $\mathrm{Zn}\left(\mathrm{SO}_{4}\right)_{2} \cdot 7 \mathrm{H}_{2} \mathrm{O}$.

Chemical modification of divinyl rubber by oxidative chhrophosphorylaton with $\mathrm{PCl}_{3}$

A round-bottom flask equipped with reflux condenser, mixer, cooler, thermometer and oxygen gas distributor was used in the experiment. The oxidative chloropho- 
sphorylation was performed with 5\% solution of SDR in $\mathrm{CCl}_{4}$. The reaction was carried out at $\mathrm{PCl}_{3} / \mathrm{SDR}=$ 10:1. Previously prepared 5\% solution of SDR in $\mathrm{CCl}_{4}$ was placed in the flask and oxygen (dried by $\mathrm{H}_{2} \mathrm{SO}_{4}$ ) was bubbled through reaction mixture at $7 \mathrm{~L} \cdot \mathrm{h}^{-1}$ and then the calculated amount of $\mathrm{PCl}_{3}$ was added to the reaction mixture under vigorous agitation. Escaping hydrogen chloride passed through backflow condenser cooled by ice and was trapped by $2 \mathrm{~N} \mathrm{NaOH}$. Amount of escaping hydrogen chloride was determined by titration of stripping solution with $\mathrm{HCl}$ test solution. The solvent, unreacted $\mathrm{PCl}_{3}$ and side product of reaction $\left(\mathrm{POCl}_{3}\right)$ were removed by water-jet air pump. Phosphorylation degree in the reaction has been calculated on the content of phosphorus in the resulting polymer.

\section{Synthesis of phosphoric containing polymer sorbent (PCPS) based on modified divinyl rubber}

The obtained product after chlorophosphorylation of SDR was added to distilled water and hydrolysis was carried out for two hours at $60^{\circ} \mathrm{C}$. The reaction product was then washed with distilled water up to neutral $\mathrm{pH}$ and dried in vacuum oven at $50^{\circ} \mathrm{C}$. The obtained powdery product had dark brown color. Prepared polymeric material containing phosphoric functionalities can be kept in dried form in desiccator or in $\mathrm{H}^{+}$form in water medium depending on purpose.

\section{Characterization of chlorophosphorylated SDR and PCPS}

The nature and distribution of functional groups in the chlorophosphorylated SDR, as well as the nature of the spatial network in the PCPS were studied by the method of NMR spectroscopy. NMR spectral measurements were carried out on a BRUKER spectrometer with the following operating frequencies: ${ }^{1} \mathrm{H}, 300 \mathrm{MHz} ;{ }^{13} \mathrm{C}, 75$ $\mathrm{MHz}$; and ${ }^{31} \mathrm{P}, 12.4 \mathrm{MHz}$. The IR spectral studies of PCPS were carried out on a Varian 3600 FTIR spectrometer at the range of $450-4000 \mathrm{sm}^{-1}$. Thermal analysis of PCPS was carried out on a NETZSCH-STA 449 F3 Jupiter. Surface images of prepared sorbents were taken by scanning microscope - RGM JEOL JCM 6430F.

\section{Preparation and analysis of metal ion solutions}

The stock solutions of metal ions have been prepared by dissolving appropriate amounts of corresponding salts in distilled water. The necessary acidity of solution $(\mathrm{pH}=3-9)$ has been created by means of acetate ammonia buffers. For $\mathrm{pH} 1$ and $\mathrm{pH} 2$ preparation the $0.1 \mathrm{~N}$ $\mathrm{HCl}$ solution has been used. The solution $\mathrm{pH}$ values were determined with a "Water Quality Checker U-10" pH-meter. The content of cations in the solutions was determined on an atomic-emission spectrometer (Optima 2100 DV “PERKIN-ELMER").

\section{Adsorption studies}

The metal ions sorption has been studied under batch experiment conditions at $25^{\circ} \mathrm{C}$ from the single metal aqueous solution. The weighed samples of sorbent $(0.05-0.5 \mathrm{~g})$ have been placed into flask and filled up with solutions of suitable electrolytes of $50 \mathrm{~mL}$ and set point of $\mathrm{pH}$, and had been stirred until the equilibrium in system was obtained. The previously determined equilibrium time was $\sim 6$ hours. After the time, the solution has been filtrated and the concentration of metals ions in filtrate has been determined. The sorption capacity (a, mmoL $-\mathrm{g}^{-1}$ ) and sorption degree ( $\mathrm{R} \%$ ) has been calculated by the following equations:

$\mathrm{a}=\left(\mathrm{C}_{\mathrm{o}}-\mathrm{C}_{\mathrm{e}}\right) \times \mathrm{V} / \mathrm{m} \quad \mathrm{R}=\left(\mathrm{C}_{0}-\mathrm{C}_{\mathrm{e}}\right) / \mathrm{C}_{\mathrm{e}} \times 100 \%$

where $C_{o}, C_{e}-$ initial and equilibrium concentration of metals ions in solution respectively, $\mathrm{mmoL} \times \mathrm{mL}^{-1}$, $\mathrm{V}$ - solution volume and $\mathrm{m}$ - amount of polymer $(\mathrm{g})$.

\section{RESULTS AND DISCUSSION}

The optimal conditions for the modification of SDR by chlorophosphorylation we established earlier ${ }^{26}$. We investigated the influence of a number of factors (the amount of $\mathrm{PCl}_{3}$, concentration of SDR in reaction mixture, oxygen flow rate, temperature and time). $\mathrm{HCI}$ is not emitted if SDR solution contacts with $\mathrm{PCl}_{3}$ in the absence of oxygen. An exothermic reaction with escaping $\mathrm{HCl}$ was observed when oxygen was bubbled through reaction mixture and temperature rose up to $333 \mathrm{~K}$. Phosphorylation degree of SDR depends on the feed rate of oxygen, temperature and duration of reaction. At the ratio of SDR : $\mathrm{PC1}_{3}=1: 10$, a flow rate of oxygen $7 \mathrm{~L} \times \mathrm{h}^{-1}$ and duration 7-8 hours the phosphorus content in the resulted material increases up to $11 \%$. Increasing the temperature in the reaction medium to the boiling point of $\mathrm{PC}_{3}(347 \mathrm{~K})$ causes decreasing the reaction rate of chlorophosphorylation. It can be explained by the fact that at high temperatures the amount of dissolved oxygen in the solution decreases. With increasing flow rate of oxygen chlorophosphorylation of SDR proceeds with high speed and for 1 hour the reaction medium darkens and becomes a solid mass. The resulting polymer with $-\mathrm{POCl}_{2}$ groups, and its hydrolysis products with $-\mathrm{PO}(\mathrm{OH})_{2}$-groups are not soluble in organic solvents, acids and alkaline solutions. This implies that, along with phosphorylation also occur crosslinking polymer chains, resulting in formation of polymer with a spatial structure.

\section{$N M R$ Spectra of initial and chlorophosphorylated SDR samples}

The sorption properties, that is, capacity and selectivity, are defined by such characteristics as the nature of functional groups, their distribution and state of the phosphorus in the matrix, which depend on the selection of initial components, their ratio, the method and conditions of their synthesis. The NMR spectroscopy is the most informative method which can provide detailed information about the structure, reaction state, and chemical environment of molecules. It was observed that oxidative chlorophosporylation of SDR leads rapidly to the cross-linking of polymer chains and heterogenization of reaction mixture. For this reason, the samples of low conversion degree (before heterogenization) have been investigated by the NMR spectroscopy for the determination of structure and location of phosphoric functionalities and cross-linking stages. $\mathrm{CCl}_{4}$ was used as solvent (outside standard was $\mathrm{D}_{2} \mathrm{O}$ ). The chlorophosphorylated SDR samples $(b, c, d)$ were taken from reaction mixture after certain period of time.

The ${ }^{1} \mathrm{H},{ }^{13} \mathrm{C}$, and ${ }^{31} \mathrm{P}$ NMR spectra of initial (a) and chlorophosporylated SDR samples $(b, c, d)$ are shown in Figures 1-3. As seen from Figure la, in initial rubber 


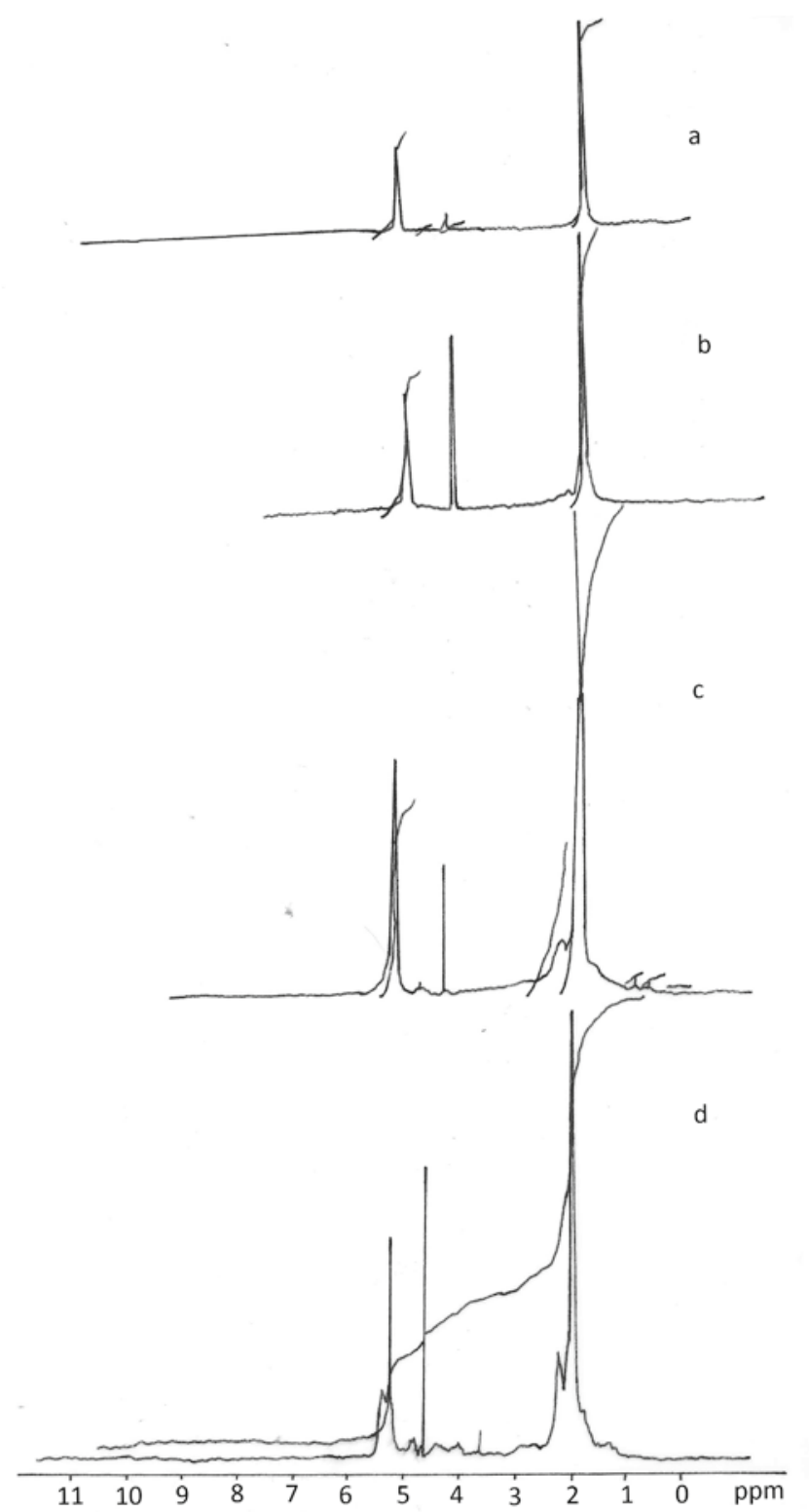

Figure 1. NMR ${ }^{1} \mathrm{H}$ - spectra of initial (a) and chlorophosporylated SDR samples (b, c d)

the ratio of the areas of resonance fields of aliphatic protons and olefinic protons is $\sim 2$, i.e. in the elementary unit 2 olefin protons correspond to each 4 aliphatic protons. In the spectrum of the first chlorophosporylated SDR sample (Figure lb) a peak corresponding to the $\mathrm{CH}-$ protons is observed $(\sim 2.3 \mathrm{ppm})$. However, the ratio of protons of- $\mathrm{CH}_{2}-$ and $=\mathrm{CH}-$ groups does not change, so, it can be concluded that at the initial stage of reaction, $\mathrm{C}-\mathrm{H}$ bond formation occurs due to both modification of hydrogen atoms in $\alpha$ - position with regard to $\pi-$ bond and addition to $\pi-$ bond. Under relatively deep conversion degree (Figure lc) the proton ratio of $-\mathrm{CH}_{2}$ - and $=\mathrm{CH} \sim$ groups increases up to $\sim 2.8$. With continuation of the reaction this ratio reaches $\sim 3.4$ (Figure 1d), i.e. the reaction mainly proceeds with the addition on double bonds. The spectrum of this sample consists of four resonance regions: an intensive signal in $-5.3 \mathrm{ppm}$-region can be referred to diene groups; low-intensive signal in $\sim 2.8-5.0 \mathrm{ppm}$ region belong to $>$ CH-P $(2.8 \mathrm{ppm}),>\mathrm{CH}-\mathrm{Cl}(\sim 4.1$ and $4.5 \mathrm{ppm})$ and $>\mathrm{CH}-\mathrm{O}(\sim 4.8 \mathrm{ppm})$ groups and a wide signal in $\sim$ 1.6-2.5 ppm region can be referred to aliphatic groups. A low-intensive signal in $\sim 10 \mathrm{ppm}$ region likely belongs

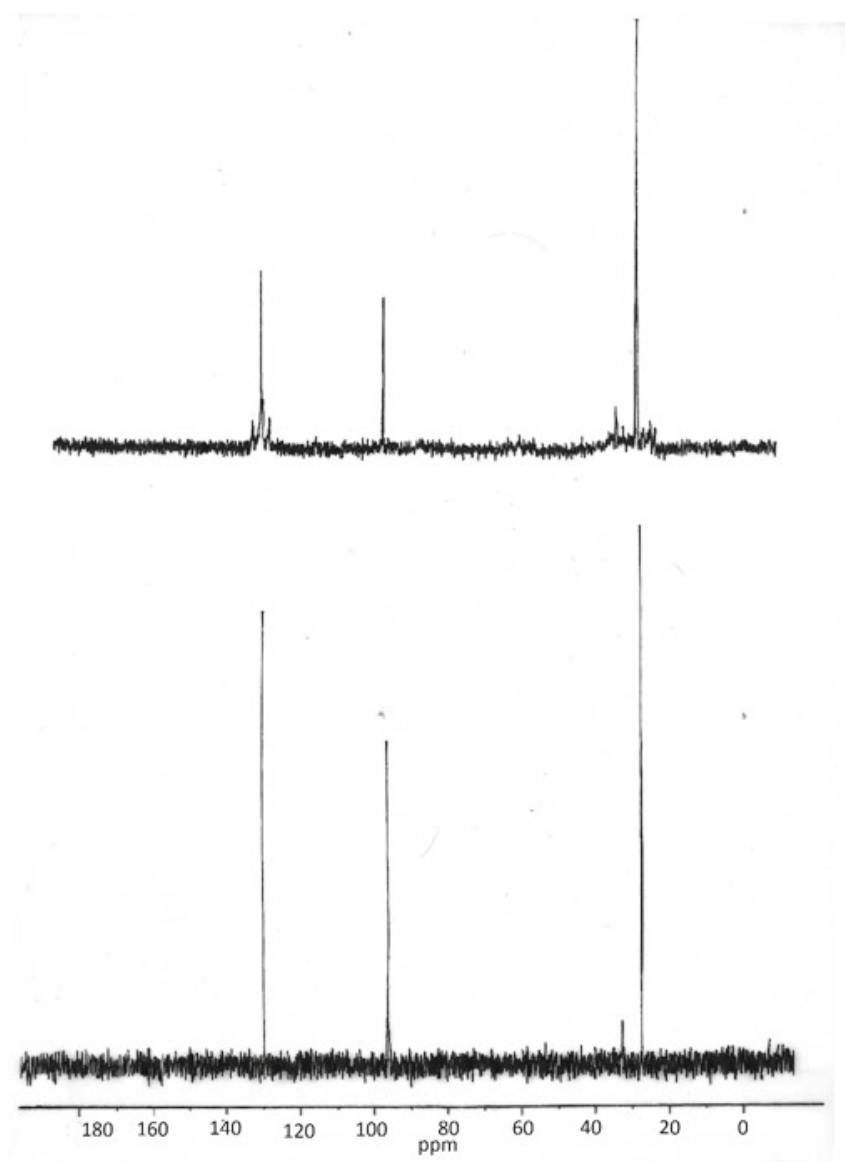

Figure 2. $\mathrm{NMR}{ }^{13} \mathrm{C}$ spectra of initial (a) and chlorophosporylated SDR (b) sample

to acidic protons in $\mathrm{P}-\mathrm{OH}$ groups, which were formed as a consequence of $\mathrm{P}-\mathrm{Cl}$ bond hydrolysis under the influence of trace amounts of moisture present in the medium.

In Figure $2 \mathrm{NMR}{ }^{13} \mathrm{C}$ spectrum of initial (2a) and chlorophosphorylated SDR samples $(2 b)$ have been presented. As seen from Figure 2, in spectrum 5 signals are observed. One of them corresponds to the double bonds $(\sim 130 \mathrm{ppm})$, but the rest of the signals belong to aliphatic fragments. Upon comparing this spectrum with the spectrum of initial rubber (Figure 2a), along with signals (28-33 ppm) corresponding to $-\mathrm{CH}_{2}-\mathrm{CH}_{2}-$ groups, the following group signals are also found out: $>\mathrm{CH}-\mathrm{POCl}_{2}(\sim 43 \mathrm{ppm}) ;>\mathrm{CHCl}(\sim 57-63 \mathrm{ppm})$; $>\mathrm{CH}-\mathrm{O}-\mathrm{POCl}_{2},>\mathrm{CHOH},>\mathrm{CHO}-(\sim 78-87 \mathrm{ppm})$. The spectrum contains the alcoholic $(>\mathrm{CHOH})$ and $>\mathrm{CHO}$ groups as well. The alcoholic groups are formed as a result of free-radical oxidation and transformation; but $>\mathrm{CHO}$ groups can be formed as a result of intermolecular bonding. These facilities are confirmed by NMR ${ }^{31} \mathrm{P}$ spectrum for chlorophosphorylated SDR (Figure 3). In the NMR ${ }^{31} \mathrm{P}$ spectrum of chlorophosphorylated SDR, along with a wide signal of $>\mathrm{CH}-\mathrm{POCl}_{2}$ group $\left(\sim 50 \mathrm{ppm}\right.$ with regard to $\left.\mathrm{PCl}_{3}\right)$, an intensive signal $8 \mathrm{ppm}$ ), corresponding to $>\mathrm{CH}-\mathrm{O}-\mathrm{POCl}_{2}$ groups, are observed. On account of relatively high mobility of the phosphordichloride groups bonded to polymer through the oxygen bridge, the width of the corresponding signals is essentially less in comparison with the signals of $>\mathrm{CH}-\mathrm{POCl}_{2}$ groups. In this case, two types of signals of various widths are observed which are related to the groups with different mobility. Hence, it is clear that even under the low degrees of transformations, phosphonic 


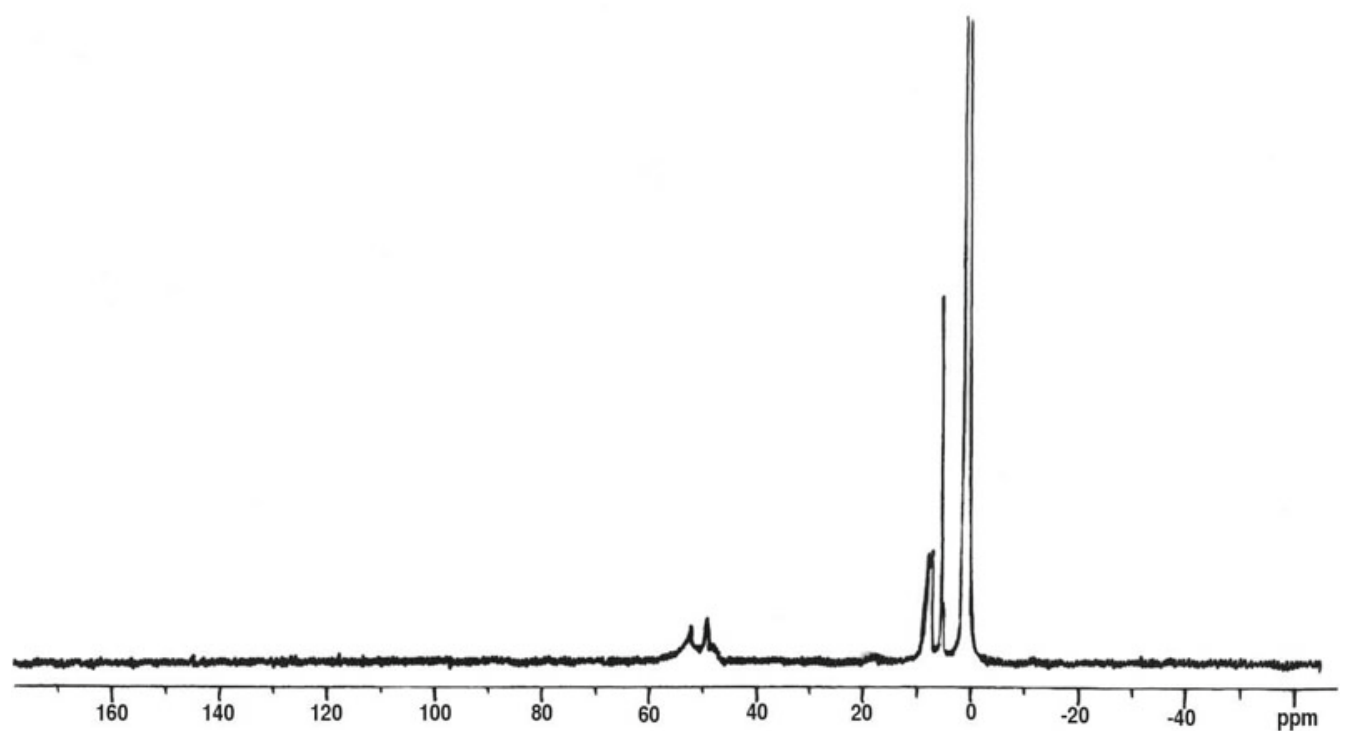

Figure 3. NMR ${ }^{31} \mathrm{P}$ spectrum of chlorophosporylated SDR

and phosphinic groups are present in both, more and less mobile regions of the polymeric matrix. It confirms the fact that the processes of chlorophosphorylation and cross-linking proceed simultaneously from the very outset of the reaction.

\section{FTIR spectra of PCPS}

The main attention in the IR-spectroscopy studies was given for identification of valence and deformation vibrations corresponding to $\mathrm{P}=\mathrm{O}, \mathrm{P}-\mathrm{OH}$ and $\mathrm{OH}$ groups. The FTIR spectrum of PCPS is presented in Figure 4. In $1200-1150 \mathrm{~cm}^{-1}$ region adsorption bands can be assigned to $\mathrm{P}=\mathrm{O}$ vibrations attracted to $\mathrm{H}$ bonds. Relatively wide adsorption band can be explained by overlapping the hydrogen bonds of different force. The adsorption bands in 1771, 2346, 2875 and $3435 \mathrm{~cm}^{-1}$ region are attributed to $\mathrm{OH}$ valence vibration of $-\mathrm{PO}(\mathrm{OH})_{2}$ groups. The observed adsorption bands of 3398 and $2857 \mathrm{~cm}^{-1}$ region indicate the strong hydrogen bond in these groups.
Adsorption band of $995 \mathrm{~cm}^{-1}$ region, corresponding to $\mathrm{C}-\mathrm{O}-\mathrm{P}$ bond indicates the bonding of $-\mathrm{PO}(\mathrm{OH})_{2}$ group to the polymer chain by means of oxygen.

\section{Electron microscope analysis}

Surface and internal structures of sorbent have been studied by scanning electron microscopy. The 750 and 1000 time increased pictures of PCPS are given in Figure 5. The obtained sorbent contains the micro-, mezo- and macro pores.

\section{Thermal analysis}

In order to know the operating temperature range of the potential sorbents the destructive transformations of PCPS samples were investigated. The TG and SDR methods have been used.

As seen from Figure 6, during thermal destruction of PCPS under argon atmosphere three temperature ranges were marked. For the first temperature range (up to $160^{\circ} \mathrm{C}$ ) mass loss is accompanied by appearance of endo-effect and arises from elimination of solvent and

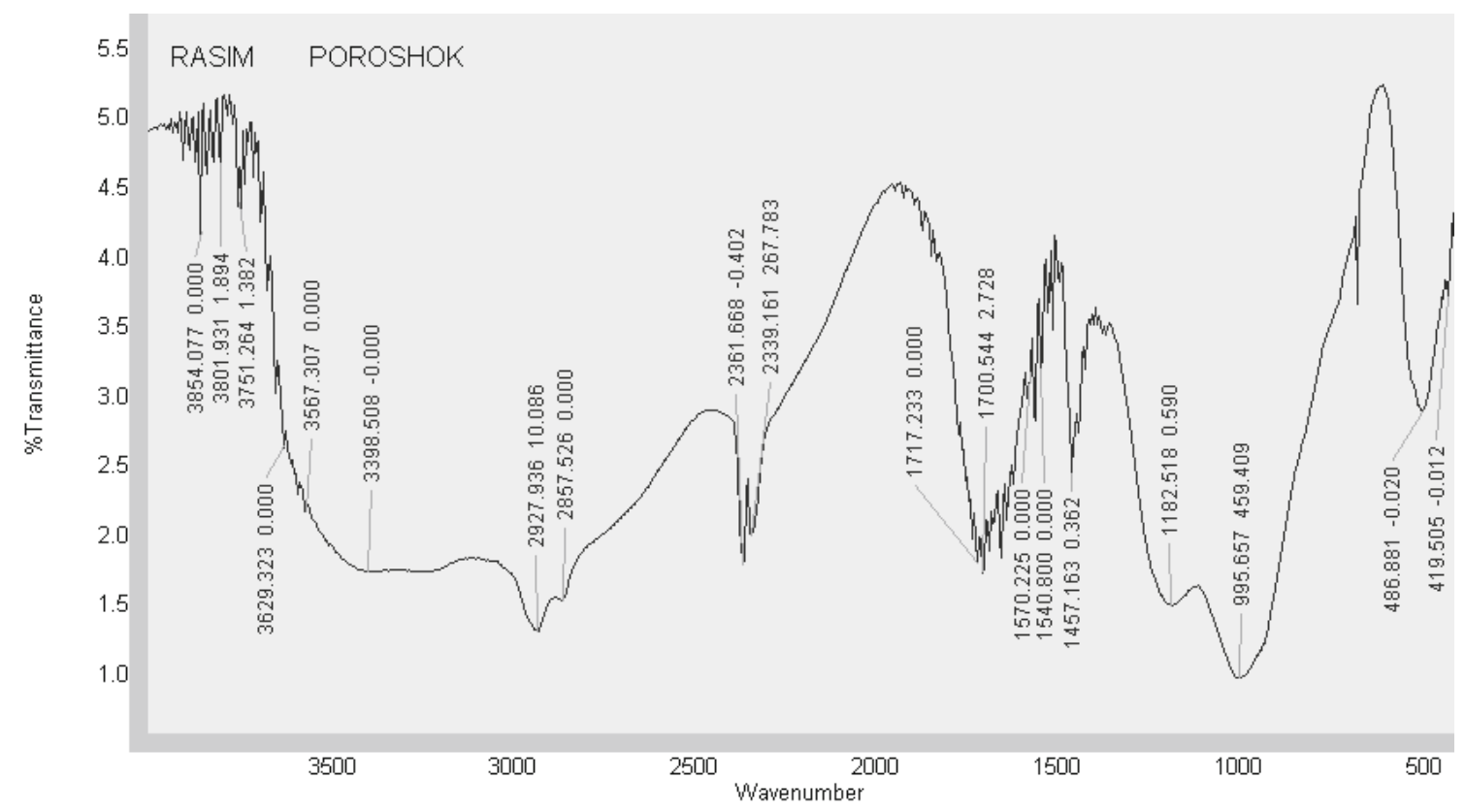

Figure 4. FTIR spectrum of PCPS 


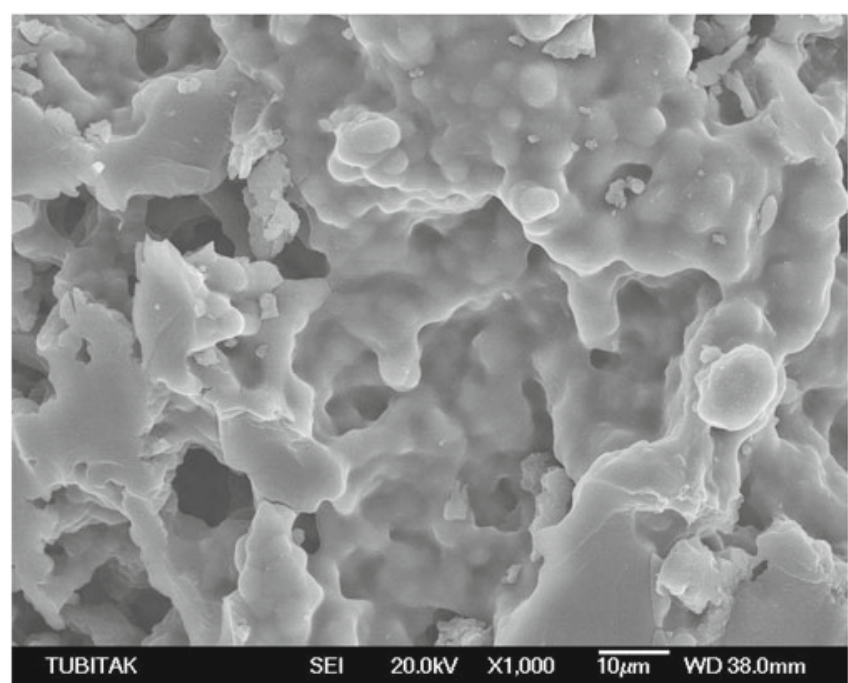

Figure 5. Electron microscope images of PCPS

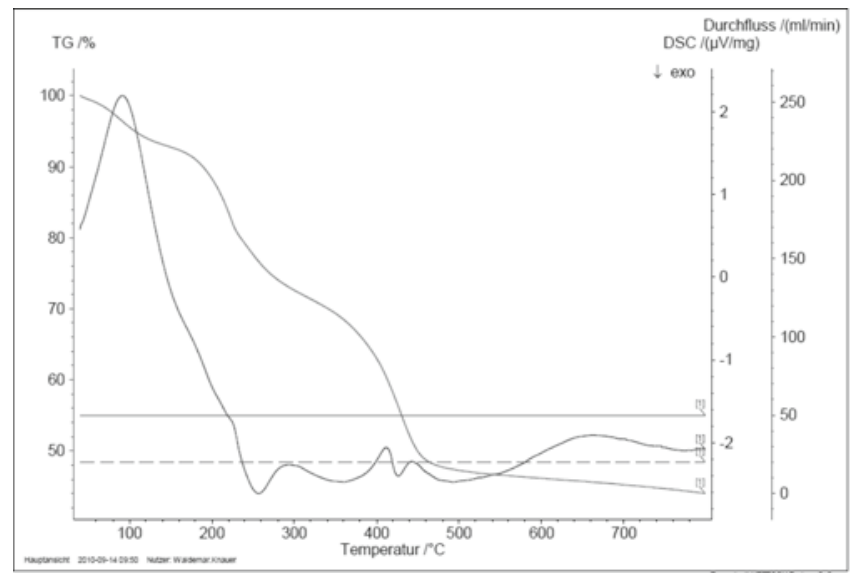

Figure 6. TG and DSC curves of PCPS in argon atmosphere

water from polymer. The second temperature interval on TG curve corresponds to $160-330^{\circ} \mathrm{C}$ temperature range. In this temperature range two processes take place: at $160-330^{\circ} \mathrm{C}$ and $230-330^{\circ} \mathrm{C}$ have been observed on SDR curve. The first process accompanied by endo- and the second by exo-effects. These processes occur due to dehydration and dephosphorylation. The third temperature interval on TG curve corresponds to the range $330^{\circ} \mathrm{C}$ and above. It has been determined that 3 thermal effects on SDR curve corresponded to these range which lead to exo-effects and confirm the identical nature of running processes. In that moment the destruction of polymer matrix has been observed. The observed different effects on SDR curve can be determined as a result of breakage of various types of chemical bonds.

\section{The effect of $\mathrm{pH}$ value on sorption degree of PCPS}

The value of sorbent sorption capacity is determined in many respects by aqueous phase acidity. Consequently, the effect of medium $\mathrm{pH}$ on PCPS removal efficiency of heavy metals from aqueous solutions has been investigated. The Figure 7 presents the dependence of $\mathrm{Cu}^{2+}$, $\mathrm{Ni}^{2+}, \mathrm{Co}^{2+}$, and $\mathrm{Zn}^{2+}$ metal ions sorption by PCPS. In more acidic field $(\mathrm{pH}<3)$ relatively low sorption degree for the shown group of metal ions is observed. It can be explained by metal presence in this range of $\mathrm{pH}$ as an aqua complex form $\left[\mathrm{Me}\left(\mathrm{H}_{2} \mathrm{O}\right)_{\mathrm{n}}\right]^{2+}$ and sorption proceeds mainly as a result of ion coordination with $-\mathrm{P}=\mathrm{O}$ groups. However, these groups are also active
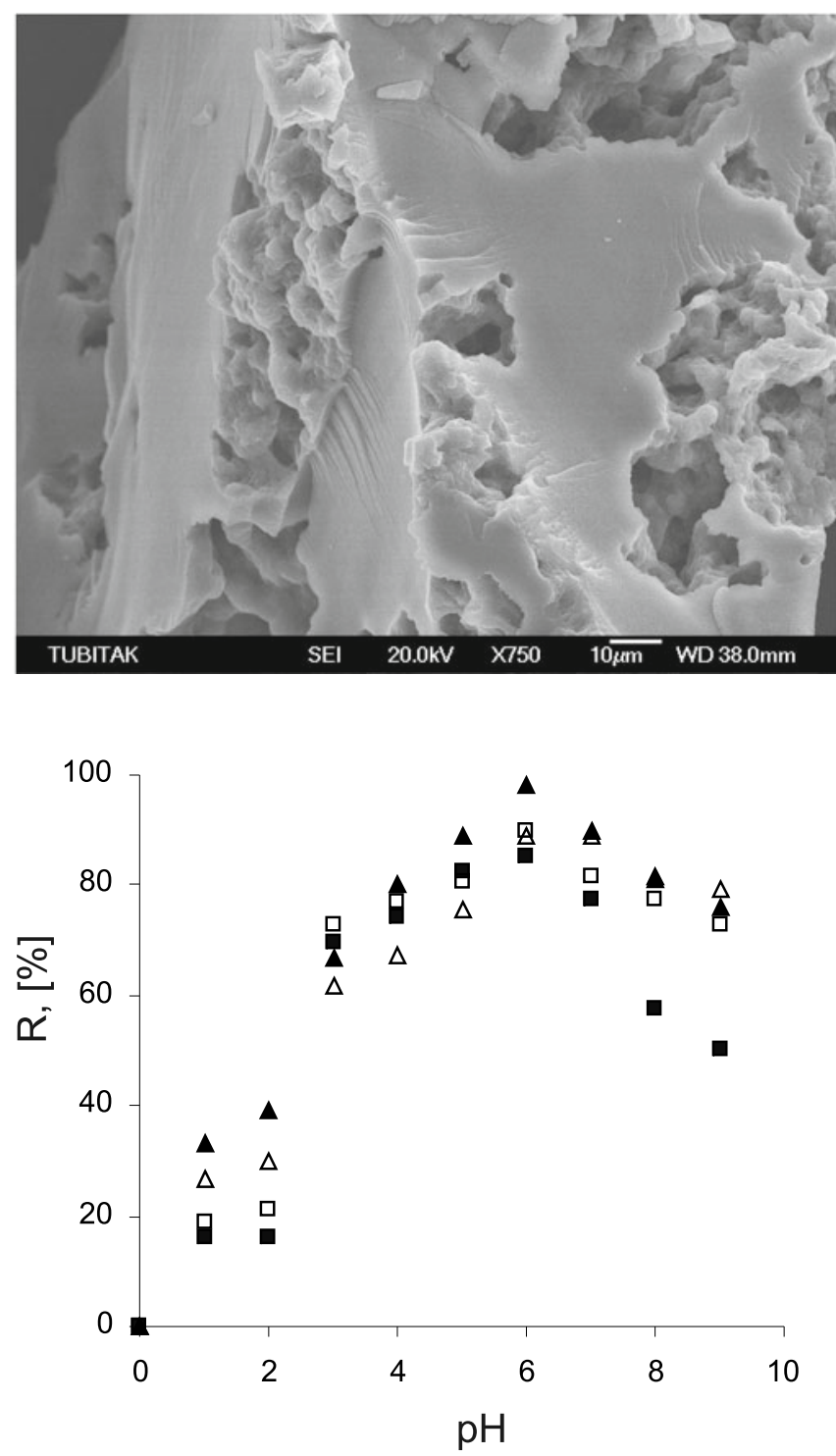

Figure 7. Effect of $\mathrm{pH}$ on the sorption of metal ions: $\boldsymbol{\Delta}-\mathrm{Ni}^{2+}$; $\Delta-\mathrm{Cu}^{2+} ; \mathrm{\square}-\mathrm{Co}^{2+} ; \mathbf{\square}-\mathrm{Zn}^{2+}$

centers for protons owing to hydrogen bonds formation $-\mathrm{P}=\mathrm{O} \times \times \times \times \times \mathrm{H}^{+}$, which causes displacement of metal ions. On another hand, sorbent has low swelling in this range of $\mathrm{pH}$. With the decrease of solution acidity in the interval of $\mathrm{pH}=3-9$ metal ions sorption degree gradually increases, reaches maximum at $\mathrm{pH}$ 6. Sorption proceeds owing to ion-coordination and/or ion interaction, partial transformation of existing aqua complexes to hydrocomplexes $\left(\left[\mathrm{Me}(\mathrm{OH})\left(\mathrm{H}_{2} \mathrm{O}\right)_{\mathrm{n}-1}\right]^{+}\right)^{27}$. But in view of that creation of $\mathrm{pH}>3$ value has been realized by means of acetate-ammonia buffer, in this range formation of both ammonium and acetate complexes of different composition, structure and stability is possible. Therefore, metals ions in solution at $\mathrm{pH}>3$ value will be present in the form of aqua, hydroxo- and ammonium complexes. The ratio of these complexes differs for different values of $\mathrm{pH}$ mediums. The optimal values of metals ions sorption is obtained at $\mathrm{pH}$ values corresponding to that state of metal ions when ammonium complexes in the form of $\left(\mathrm{Me}\left(\mathrm{NH}_{3}\right)^{2+}\right)$ dominate in solution. When $\mathrm{pH}$ value increases, their moiety decreases in solution. That can be considered a reason of sorption decrease in alkali solutions. These results confirm that synthesized material containing different phosphoric functionalities could be used as effective polyfunctional sorbent for 
metal removal from various aqueous mediums in wide range of $\mathrm{pH}$ values and concentration of the metal ions.

\section{The effect of the initial amount of PCPS to its sorption properties}

The studies on effect of the initial amount of PCPS to its sorption properties were done at $\mathrm{pH} 6$, which corresponds to $\mathrm{pH}_{\mathrm{opt}}$ for investigated metal ions. The volume of solution was $90 \mathrm{~mL}$ with initial concentration of metal ions ImmoL $\cdot \mathrm{L}^{-1}$. Different amounts of PCPS on the range of $0.05-0.50 \mathrm{~g}$ were tested. As can be seen from Figure 8, with increasing initial amount of sorbent its extraction degree increases.

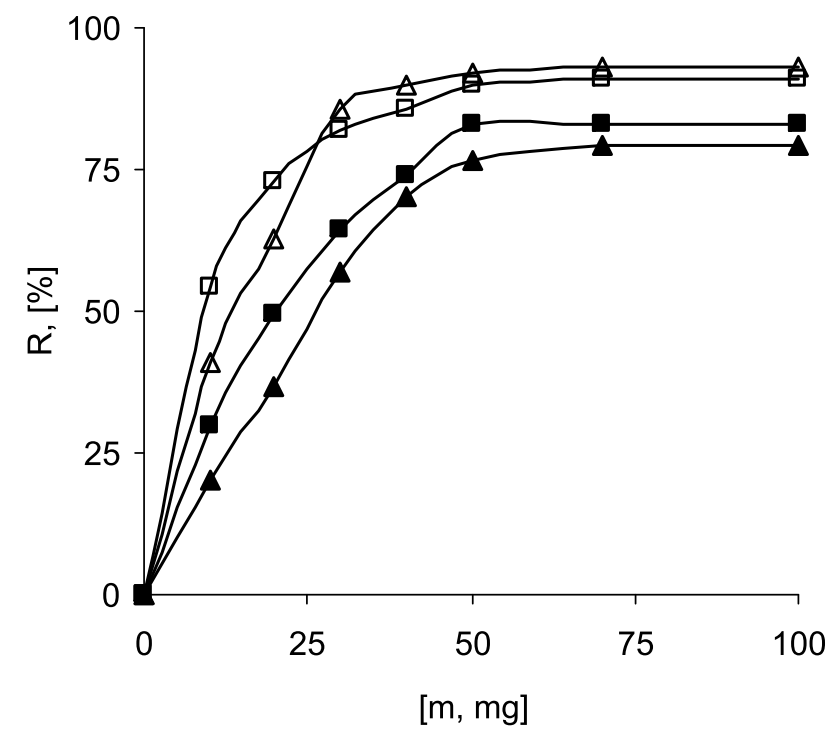

Figure 8. Effect of sorbent weight on the sorption of metal ions: $\Delta-\mathrm{Ni}^{2+} ; \Delta-\mathrm{Cu}^{2+} ; \mathbf{\square}-\mathrm{Co}^{2+} ; \mathbf{-}-\mathrm{Zn}^{2+}$

The effect of the initial concentration of the metals ions in solution to the sorption degree of PCPS

The effect of initial concentration of metals ions in solution to the sorption degree has been studied. For that, $0.30 \mathrm{~g}$ of sorbent was placed into buffer solution with $\mathrm{pH} 6$ and calculated amount of metal ions solution were added to bottle for creation the conditions for optimal sorption. As presented in Figure 9, with incre-

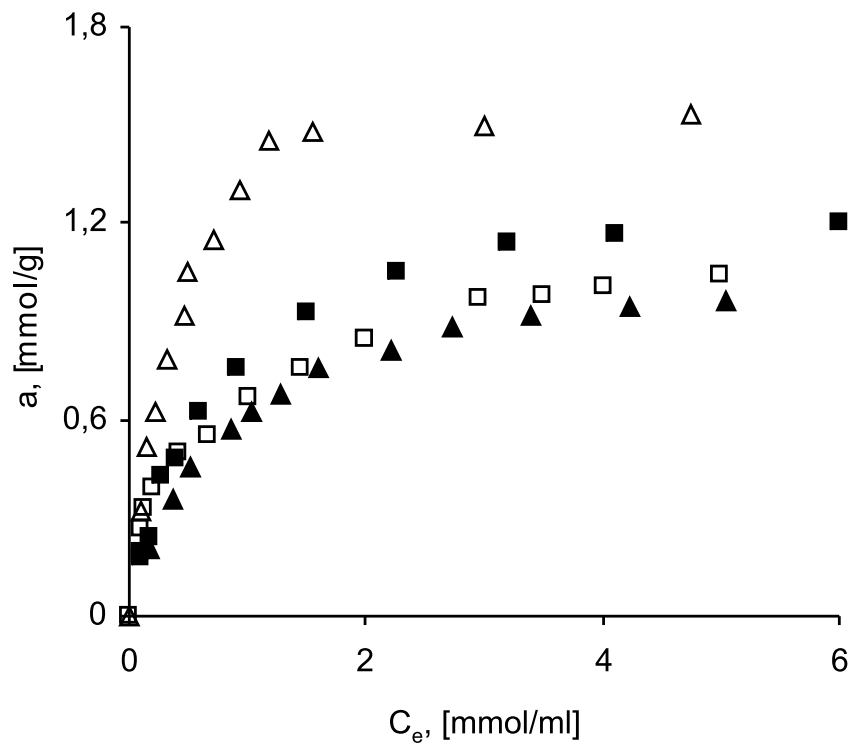

Figure 9. Effect of sorbent weight on the sorption of metal ions: $\Delta-\mathrm{Ni}^{2+} ; \Delta-\mathrm{Cu}^{2+} ; \mathbf{\square}-\mathrm{Co}^{2+} ; \mathbf{\square}-\mathrm{Zn}^{2+}$ asing initial metal ion concentration in the solution an increase of their adsorption is observed. Three sites can be distinguished on the isotherms. Initial, abruptly rising upwards, almost linear site of the curve indicates that at low concentrations the sorption is practically proportional to this value. At the same time, the metal ion monolayer on the sorbent surface is formed. The almost horizontal site, corresponding to the higher concentrations, satisfying sorbent surface, is completely saturated by metal ion. In these conditions, the amount of adsorbed cations does not depend on their concentration if only monolayer of metal ions forms on the sorbent surface. The middle site of isotherm corresponds to average sorption degree of PCPS. The results indicated that the affinity order of sorption for investigated group of metal ions was observed as follows: $\mathrm{Cu}^{2+}>\mathrm{Zn}^{2+}>\mathrm{Co}^{2+}>\mathrm{Ni}^{2+}$.

\section{CONCLUSION}

New low cost polyfunctional phosphorus-containing material including $-\mathrm{PO}(\mathrm{OH})_{2},-\mathrm{OPO}(\mathrm{OH})_{2}$ groups were prepared by oxidative chlorophosphorylation of industrial polymer- divinyl rubber with $\mathrm{PCl}_{3}$ followed by hydrolysis of obtained products. Physico-chemical analysis of a structure of prepared material demonstrated that the phosphonic and phosphinic groups are present in both, more and less mobile regions of the polymeric matrix, which confirms the fact that the processes of chlorophosphorylation and cross-linking of polymer chain proceed simultaneously from the very outset of the reaction.

The nature of functional groups of obtained material predetermines their universal extracting, removing and concentrating properties of heavy metal ions. The sorption capability of modified divinyl rubber towards cations $\mathrm{Cu}^{2+}>\mathrm{Zn}^{2+}>\mathrm{Co}^{2+}>\mathrm{Ni}^{2+}$ from aqueous solutions have been tested in different values of $\mathrm{pH}$ and concentrations of the metal ions in solution. The results confirm that synthesized material containing phosphoric functionalities could be used as effective polyfunctional sorbent for metal removal from various aqueous mediums in wide range of $\mathrm{pH}$ values and concentration of the metal ions.

\section{ACKNOWLEDGEMENT}

The authors wish to thank King Abdulaziz City for Science \& Technology, Riyadh, Kingdom of Saudi Arabia, for financial support of this research project.

\section{LITERATURE CITED}

1. Cullen, M R., Jobinds, J.M. \& Eskrnazi B. (1983) Adult inorganic lead intoxication: presentation of 31 new cases and a review of recent advances in the literature. Medicin., 62(4), 221-247.

2. Dunnick, J.K. \& Fowler B.A. (1988). Toxicity of Inorganic Compounds. New York: Marcel Dekker.

3. Yavuz, M., Gode, F., Osmert, S. \& Sharma Y. (2008). An economic removal of $\mathrm{Cu}^{2+}$ and $\mathrm{Cr}^{2+}$ on the new adsorbents: Pumice and polyacrilonitrile/pumice composite. Chem. Eng. ..., 137, 453-461. doi:10.4236/jwarp.2010.24037

4. Mulder, M. (1996). Basic Principles of membrane Technology ( $2^{\text {nd }}$ ed.J. Holland: Kluwer Academic Publisher. doi:10.1002/ recl.19921111015

5. Cushinie, C. (1987). Removal of metals from wastewater: neutralization and precipitation. USSR: Metallurgy publisher. 
6. Koqanovskiy, M.A. (1983). Adsorbtsiya i ionniy obmen v protsessax vodopodqatovki i otsistki stochonix vod. Kiev: Naykova Dumka publisher.

7. Asouhidou, D. D., Triantafyllidis, K.S., Lazaridis, N. K.\& Matis, K. A. (2012). Adsorption of reactive dyes from aqueous solutions by layered double hydroxides. J of Chem. Techno/, and Biotech. 87(4), 575-582. doi:10.1002/jctb.2755 (2012).

8. Guixia, Z., Xilin, W., Xiaoli, T. \& Xiangke, W. (2011). Sorption of Heavy Metal Ions from Aqueous Solutions: A Review. The Open Coll. Sci. J. 4, 19-31.

9. Soylak M., Elci L., Dogan M. (1996). Determination of Some Trace Metal Impurities in Refined and Unrefined Salts after Preconcentration onto Activated Carbon, Fresenius Environmental Bulletin, 5, 148-155.

10. Elci L., Soylak M., Uzun A., Buyukpatir E., Dogan M. (2000). Determination of Trace Impurities in Some Nickel Compounds by Flame Atomic Absorption Spectrometry after Solid Phase Extraction Using Amberlite XAD-16 Resin, Fresenius Journal of Analytical Chemistry, 368, 358-361.

11. Tuzen M., Saygi K.O., Soylak M. (2008). Novel Solid Phase Extraction Procedure for Gold(III) on Dowex M 4195 prior to its Flame Atomic Absorption Spectrometric Determination, Journal of Hazardous Materials, 156, 591-595. doi:10.1016/j. jhazmat.2007.12.062

12. Hackman, E. (1978). Toxic Organic Chemicals: Destuction and Waste Treatment. New Jersey: Noyes Data Corporation. doi: 10.5897/ajb05.419

13. Kumaru, E., Kurogi, Y. \&Takahashi, T. (1991).The first gold(III) macrocyclic polyamine complexes and application to selective gold(III) uptake. Inorg. Chem. 30 (22),4117-4121. doi: $10.1021 / \mathrm{ic} 00022 \mathrm{a} 007$.

14. Sirivastava, S. K., Gupta, V. K. \& Jain. S. (1995).Determination of lead using polyvinyl chloride) based crown ether membrane. Analyst. 120(2), 495-498. doi:10.1039/AN9952000495.

15. Soylak, M., Elci, L.\& Dogan, M. (2000). A sorbent extraction procedure for the precon- centration of gold, silver and palladium on an activated carbon column. Anal. Lett. 33, 513-525. doi: 10.1080/00032710008543070

16. Benyahya, I. \& Gamier, J. (1999).Effect of salicylic acid upon trace-metal sorption $\left(\mathrm{Cd}^{2+}, \mathrm{Zn}^{2+}, \mathrm{Co}^{2+}\right.$, and $\left.\mathrm{Mn}^{2+}\right)$ onto Alumina, Silica, and Kaolinite as a function of pH. Environ. Sci.\& Technol. 33(9), 1398-1407. doi:10.1016/j.chemgeo.2007.03.002 17. Ahmetli, G.\& Tarlan, E. J. (2007). Fe (II/III) adsorption onto styrene/divinylbenzene based polymers. Appl. Polym. Sci. 104, 2696-2703. doi: 10.1002/app.25982

18. Dyer, A. (2000). Encyclopedia of Separation Science. New York: Academic Press.

19. Deveci, H., Ahmetli, G., Ersoz, M. \& Kurbanli, R. (2009). Synthesis and metal ions sorption properties of styrene-based polymers. Appl. Polym. Sci. 112, 1192-1198. doi: 10.1002/ app.29511

20. Kanwal, F., Imran, M., Mitu, L., Rashid, Z. \& Razza, H. (2012). Removal of Chromium (III) using synthetic polymers, copolymers and their sulfonated derivatives as adsorbents [Abstract] E-J of Chem. 9(2), 621-630. From Hindawi Publishing corporation on http://dx.doi.org/10.1155/2012/857579.

21. Arsalani, N., Rakh, R., Ghasemi, E. \& Entezami, A. (2009) Removal of $\mathrm{Ni}$ (II) from synthetic solutions using new amine-containing resines based on polyacrylonitrile. Iranian Pol. J. 18, 623-632.

22. Trochimczuk, A. (1998). Novel ion-exchange coordination resines with carboethyl phosphonate ligands. Eur. Polym. J. 34(7), 1047-1051. doi: 10.1016/s0014-3057(97)00218-8

23. Trochimczuk, A. \& Jezierska J.(1997). Selective hydrolysis of polymer-bound ethoxy- carbonylethyl phosphonate and EPR studies of copper (II) complexes with the parent resin and ist derivatives. Polymer. 38, 2431-2435. doi:10.1016/S00323861(96)00795-1

24. Trochimczuk, A. \& Alexandratos, S. (1994) Synthesis of bifunctional ion-exchange resins through the Arbusov reac- tion - effect on selectivity and kinetics. Appl. Polym. Sci. 52, 1273-1277. doi: 10.1002/app.1994.070520912

25. Alexandratos, S.D., Trochimczuk, A.W., Crick, D.W., Horwitz, E.P. \& Gartone, R.C. (1996). Synthesis and ion-complexing properties of a novel polymer-suppoted reagent with diphosphonate ligands. Macromolecules. 29(3), 1021-1026. doi: $10.1021 / \mathrm{ma} 950943 \mathrm{u}$

26. Azizov, A. A., Rahimov, R. A. \& Alosmanov, R.M. A.R. Patent № 2005 0142. Baku: State Committee on standard, metrology and patent.

27. Turova, N. (1997). Reference Tables of Inorganic Chemistry. Moscow: Chemistry Press. doi: 10.1007/978-3-642-20487-6_1 